\title{
Abbreviations used in references in text
}

$\begin{array}{ll}\text { DRO } & \text { Dorset Record Office } \\ \text { ESRO } & \text { East Suffolk Record Office } \\ \text { MAFF } & \text { Ministry of Agriculture, Fisheries and Food } \\ \text { Northants CRO } & \text { Northamptonshire County Record Office } \\ \text { NRA } & \text { National Rivers Authority } \\ \text { PD } & \text { Parliamentary Debates } \\ \text { PRO } & \text { Public Record Office } \\ \text { RSNC } & \text { Royal Society for Nature Conservation } \\ \text { RSPB } & \text { Royal Society for the Protection of Birds } \\ \text { WRO } & \text { Wiltshire Record Office } \\ \text { WSRO } & \text { West Suffolk Record Office } \\ \text { WWF } & \text { Wessex Water Authority }\end{array}$


